\title{
Survival Analysis
}

\section{Survival from cancer of the pancreas in England and Wales up to 2001}

\author{
E Mitry', B Rachet ${ }^{2}$, MJ Quinn ${ }^{3}$, N Cooper ${ }^{3}$ and MP Coleman*,2 \\ 'Département d'Hépatogastroentérologie et Oncologie Digestive, Centre Hospitalo-Universitaire Ambroise-Paré, 9 avenue Charles de Gaulle, F-92 I00 \\ Boulogne, France; ${ }^{2}$ Cancer Research UK Cancer Survival Group, Non-Communicable Disease Epidemiology Unit, Department of Epidemiology and \\ Population Health, London School of Hygiene and Tropical Medicine, Keppel Street, London WCIE 7HT, UK; ${ }^{3}$ Social and Health Analysis and Reporting \\ Division, Office for National Statistics (Room FG/I I 4), I Myddelton Street, London ECIR IUW, UK
}

British Journal of Cancer (2008) 99, S2I -S23. doi:I0.1038/sj.bjc.6604576 www.bjcancer.com

Published online 23 September 2008

(C) 2008 Cancer Research UK

Cancer of the pancreas accounts for some 3\% of cancer in both sexes combined, with about 6000 new cases a year (Cooper et al, 2005). The only established risk factor for pancreatic cancer is tobacco smoking (Lowenfels, 1984). Incidence has fallen some $10-15 \%$ since the mid-1970s in men but has risen slightly in women, and annual incidence in both sexes is now similar at about 10 per 100000 (Quinn et al, 2001). Both incidence and mortality rates may be biased, however, by under-registration of incident cases and an over-certification of deaths (Remontet et al, 2003). In this context, the survival of patients who were registered with a diagnosis of pancreatic cancer in life assumes particular importance as a measure of outcome. Pancreatic cancer has one of the worst prognoses: the European mean relative 5-year survival rate for patients diagnosed during 1990-1994 was less than 4\% (Sant et al, 2003).

We analysed the data for 62815 patients registered with pancreatic cancer in England and Wales during the period $1986-1999$, only $74 \%$ of those were apparently eligible. More than a fifth $(22 \%)$ of all cases had to be excluded from survival analysis because their recorded survival was zero (date of diagnosis same as date of death): some will in fact have died on the day of diagnosis, but most were registered from a death certificate only (DCO), and their survival time was unknown. Some $3 \%$ of cases in the national data were known to have been DCOs, but the proportion varied by registry, and they could not be reliably distinguished from cases with true zero survival in the national data. The proportion of cases whose recorded survival was zero rose from 12 to $14 \%$ in the 1970 s to $19-22 \%$ in the 1990 s (Coleman et al, 1999). As they represent such a large proportion of patients who were otherwise eligible for survival analysis, and who may have shorter than average survival (Berrino et al, 1995), the impact of their exclusion on observed trends and inequalities in survival needs to be considered. Nationally, the proportion of such cases fluctuated slightly within the range $19-25 \%$. Trends in the proportion of such cases, however, varied very widely among regions: stable and relatively low (6-11\%) in Northern and Yorkshire, East Anglia and Oxfordshire; initially high but falling rapidly (Thames, Wales); or initially low but rising rapidly (South and West, West Midlands).

*Correspondence: Professor MP Coleman;

E-mail: michel.coleman@|shtm.ac.uk
These patterns are hard to interpret, as the efficiency and timeliness of registration have increased over this period, and the proportion of other cancers registered solely from a death certificate has generally declined. Overall estimates of survival may thus be slightly high. In contrast, the impact of exclusions for zero survival on trends in the deprivation gap in survival during the 1990 s is likely to have been small or negligible, as there was no systematic difference in the proportion of such cases among socioeconomic groups (data not shown). The vital status of $1.4 \%$ of patients was unknown at 5 November 2002, and a further $2.8 \%$ were also excluded because pancreatic cancer was not their first primary malignancy.

\section{SURVIVAL TRENDS}

Short-term survival has increased slightly in men, but there is no evidence of improvement in longer-term survival in either sex (Figure 1). One-year survival rose slightly from around $12 \%$ for men diagnosed during the 10 years 1986-1995 to $13.9 \%$ for those diagnosed during 1996-1999. The fitted, deprivationadjusted average increase of $1.6 \%$ every 5 years was statistically significant (Table 1). For women, 1-year survival rose very slowly, from 10.9 to $12.1 \%$, with an average increase of just $0.3 \%$ every 5 years. There was, however, no improvement at all in 5-year survival, which was actually slightly lower for those diagnosed during 1996-1999 (2.7\% in men, $2.3 \%$ in women) than for those diagnosed during 1986-1990 (3.1 and 2.5\%, respectively). Median survival is less than 6 months in both sexes, and it did not improve.

Short-term predictions of survival for patients diagnosed during 2000-2001, using hybrid analysis (Brenner and Rachet, 2004), show no evidence of any pending improvement in survival up to 10 years after diagnosis (Table 1).

\section{DEPRIVATION}

Differences in survival between deprivation categories were small. For those diagnosed during the late 1990s, the deprivation gap in 1- and 5-year survival was slightly more marked in men (Table 2, Figure 2). For women diagnosed in 1996-1999, 

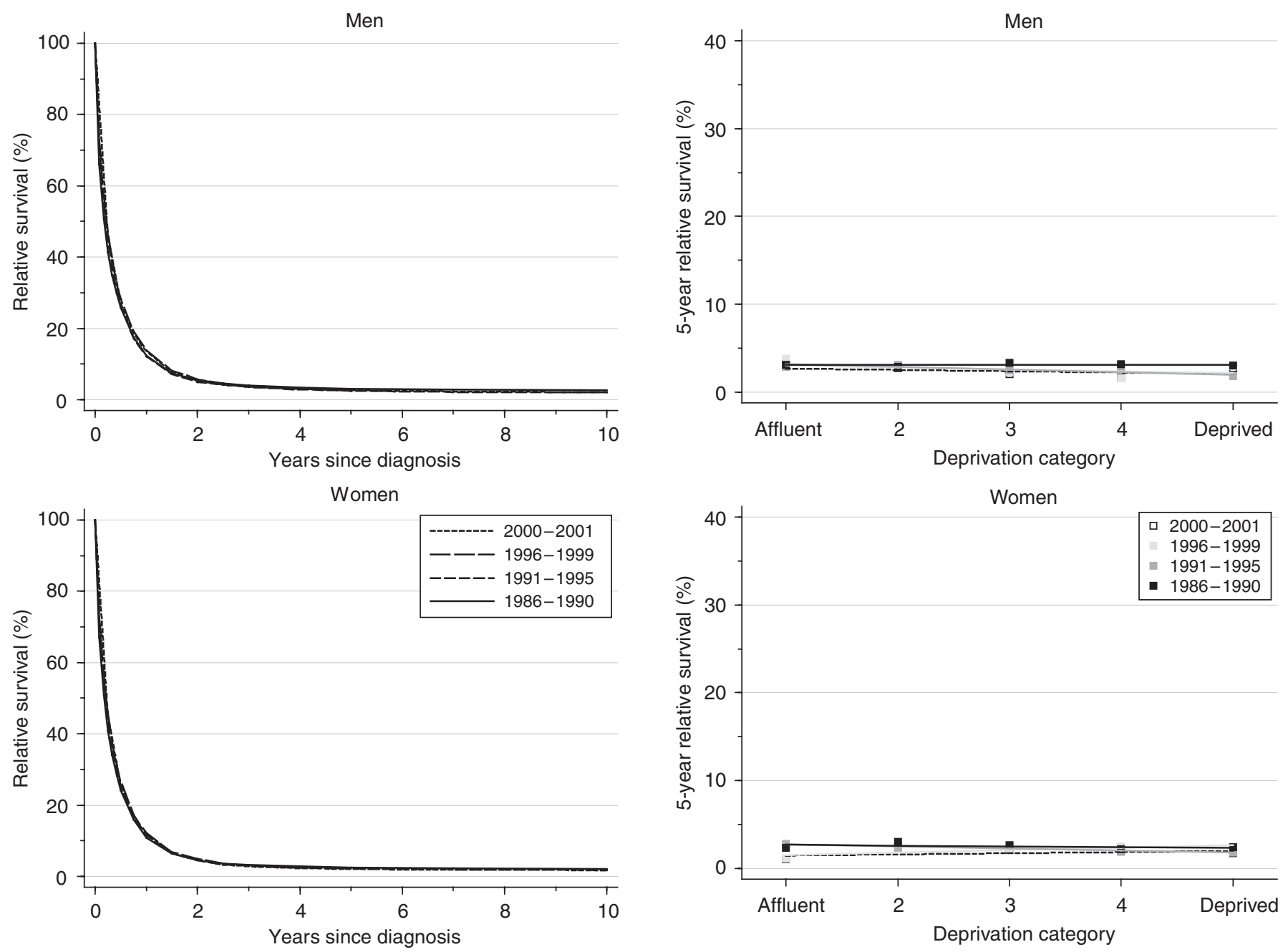

Figure I Relative survival (\%) up to 10 years after diagnosis by sex and calendar period of diagnosis: England and Wales, adults (15-99 years) diagnosed during 1986-1999 and followed up to 2001. Survival estimated with cohort or complete approach (|986-1990, |99|-1995,

Figure 2 Trends in the deprivation gap in 5-year relative survival (\%) by sex and calendar period of diagnosis: England and Wales, adults (15-99 years) diagnosed during 1986-1999 and followed up to 2001.

1996-1999) or hybrid approach (2000-200I) (see Rachet et al, 2008).

Table I Trends in relative survival (\%) by sex, time since diagnosis and calendar period of diagnosis: England and Wales, adults (I5-99 years) diagnosed during 1986-1999 and followed up to 2001

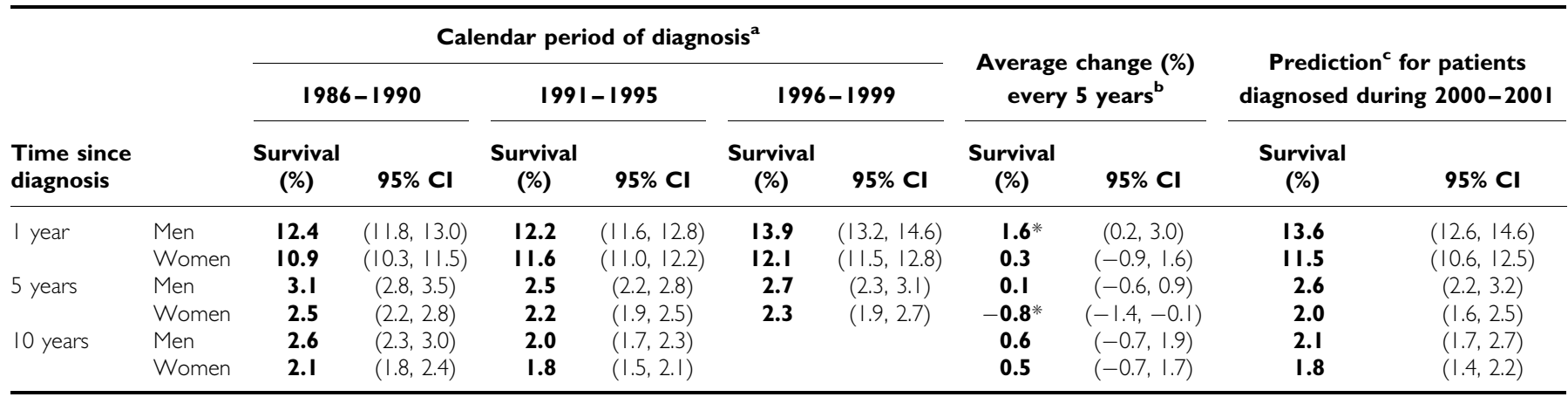

$\mathrm{Cl}=$ confidence interval. ${ }^{a}$ Survival estimated with cohort or complete approach (see Rachet et al, 2008). ${ }^{b}$ Mean absolute change (\%) in survival every 5 years, adjusted for deprivation (see Rachet et al, 2008). 'Survival estimated with hybrid approach (see Rachet et al, 2008). *P<0.05.

5 -year survival was slightly better in the deprived than the affluent (deprivation gap positive, $+1.1 \%$ ) and this difference was of borderline statistical significance. The deprivation gap in survival for women diagnosed during the 14 years 1986-1999 appears to have fallen for 1-year survival or even reversed for 5-year survival, but the fitted average improvement every 5 years was less than $1 \%$, and this trend was not statistically significant. There was no systematic trend towards better survival in the deprived than the affluent, and short-term predictions of survival for patients diagnosed during 2000-2001, using 
Survival from cancer of the pancreas in England and Wales

E Mitry et al

Table 2 Trends in the deprivation gap in relative survival (\%) by sex, time since diagnosis and calendar period of diagnosis: England and Wales, adults (15-99 years) diagnosed during 1986-1999 and followed up to 2001

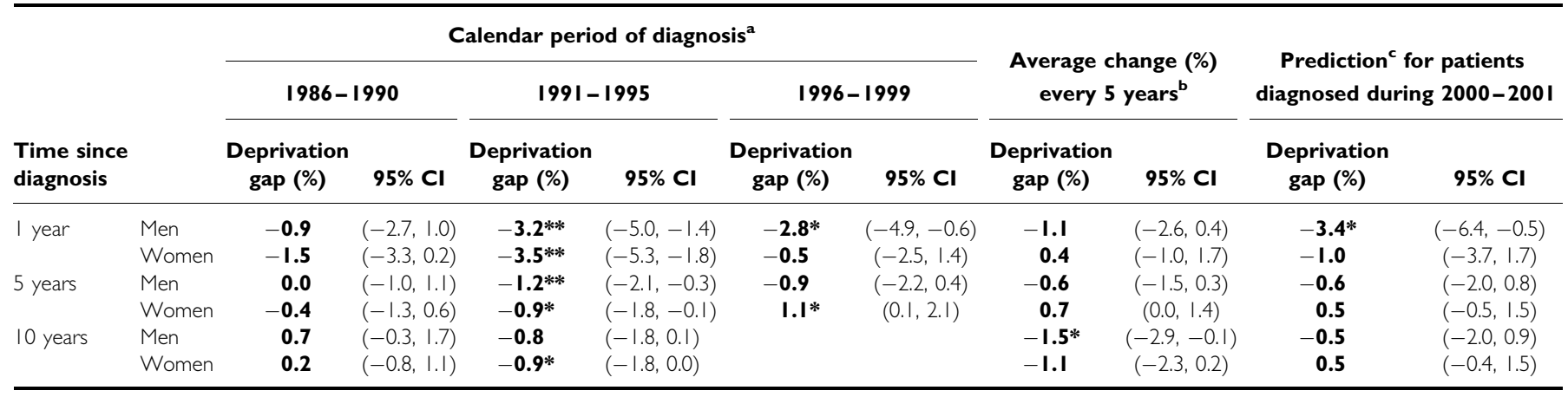

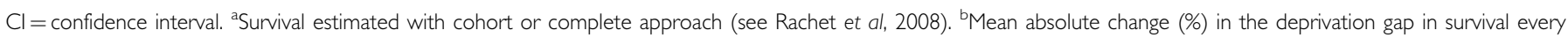
5 years, adjusted for the underlying trend in survival (see Rachet et al, 2008). 'Survival estimated with hybrid approach (see Rachet et al, 2008). * $P<0.05$; *** $P<0.01$.

hybrid analysis, do not suggest any imminent change in the deprivation gap.

\section{COMMENT}

Relative survival at 5 years, less than $3 \%$ in both sexes, is lower than for any other of the 20 most common adult cancers in England and Wales. No improvement has occurred since the 1970s (Coleman et al, 1999). Despite progress in diagnostic procedures, most cases are still metastatic at diagnosis, and are not amenable to surgical resection of curative intent. Even when curative surgery can be attempted, most patients will relapse. A small trial has shown that palliative chemotherapy may extend median survival from 2.5 to 6 months (Glimelius et al, 1996), but efficacy remains disappointing, and any therapeutic progress over the last 30 years has not been reflected in higher survival for all patients with pancreatic cancer.

\section{REFERENCES}

Berrino F, Estève J, Coleman MP (1995) Basic issues in the estimation and comparison of cancer patient survival. In Survival of Cancer Patients in Europe: the EUROCARE Study. (IARC Scientific Publications No. 132). Berrino F, Sant M, Verdecchia A, Capocaccia R, Hakulinen T, Estève J (eds), pp 1-14. International Agency for Research on Cancer: Lyon

Brenner H, Rachet B (2004) Hybrid analysis for up-to-date long-term survival rates in cancer registries with delayed recording of incident cases. Eur J Cancer 40: 2494-2501

Coleman MP, Babb P, Damiecki P, Grosclaude PC, Honjo S, Jones J, Knerer G, Pitard A, Quinn MJ, Sloggett A, De Stavola BL (1999) Cancer Survival Trends in England and Wales 1971 - 1995: Deprivation and NHS Region. Studies on Medical and Population Subjects No. 61. The Stationery Office: London

Cooper N, Gautrey M, Quinn MJ (2005) First release: Cancer: number of new cases, 2002. Office for National Statistics. http://www.statistics. gov.uk/StatBase/

Glimelius B, Hoffman K, Sjoden PO, Jacobsson G, Sellstrom H, Enander LK, Linne T, Svensson C (1996) Chemotherapy improves survival and quality of life in advanced pancreatic and biliary cancer. Ann Oncol 7: 593-600

Lowenfels AB (1984) Chronic pancreatitis, pancreatic cancer, alcohol and smoking. Gastroenterology 87: 744-745

Quinn MJ, Babb P, Brock A, Kirby L, Jones J (2001) Cancer Trends in England and Wales 1950-1999. Studies on Medical and Population Subjects No. 66. Office for National Statistics: London

Remontet L, Estève J, Bouvier A-M, Grosclaude PC, Launoy G, Ménégoz F, Tretarre B, Exbrayat C, Carli P-M, Guizard AV, Troussard X, Bercelli P, Colonna M, Halna JM, Hédelin G, Macé-Lesech J, Peng J, Buémi A, Velten M, Jougla E, Arveux P, Le Bodic L, Michel E, Sauvage M, Schwartz J, Faivre J (2003) Cancer incidence and mortality in France over the period 1978-2000. Rev épidémiol santé publique 51: 3-30

Rachet B, Woods LM, Mitry E, Riga M, Cooper N, Quinn MJ, Steward J, Brenner H, Estève J, Sullivan R, Coleman MP (2008) Cancer survival in England and Wales at the end of the 20th century. Br J Cancer 99(Suppl 1): S2-S10

Sant M, Aareleid T, Berrino F, Bielska Lasota M, Carli P-M, Faivre J, Grosclaude PC, Hédelin G, Matsuda T, Møller H, Moller T, Verdecchia A, Capocaccia R, Gatta G, Micheli A, Santaquilani M, Roazzi P, Lisi D, EUROCARE Working Group (2003) EUROCARE-3: survival of cancer patients diagnosed 1990-94 - results and commentary. Ann Oncol 14(Suppl 5): $61-118$ 